\title{
Nonlinearity Compensation for Dual-Polarization Signals using Optical Phase Conjugation in a Silicon Waveguide
}

Da Ros, Francesco; Porto da Silva, Edson; Gajda, A.; Kaminski, Pawel Marcin; Cristofori, Valentina; Pczek, A. ; Mai, A.; Petermann, Klaus; Zimmermann, L.; Oxenløwe, Leif Katsuo

Total number of authors:

11

Published in:

CLEO: Science and Innovations 2018

Link to article, DOI:

10.1364/CLEO_SI.2018.STu4C.1

Publication date:

2018

Document Version

Peer reviewed version

Link back to DTU Orbit

Citation (APA):

Da Ros, F., Porto da Silva, E., Gajda, A., Kaminski, P. M., Cristofori, V., Pczek, A., Mai, A., Petermann, K., Zimmermann, L., Oxenløwe, L. K., \& Galili, M. (2018). Nonlinearity Compensation for Dual-Polarization Signals using Optical Phase Conjugation in a Silicon Waveguide. In CLEO: Science and Innovations 2018 [Paper STu4C.1] Optical Society of America. https://doi.org/10.1364/CLEO_SI.2018.STu4C.1

\section{General rights}

Copyright and moral rights for the publications made accessible in the public portal are retained by the authors and/or other copyright owners and it is a condition of accessing publications that users recognise and abide by the legal requirements associated with these rights.

- Users may download and print one copy of any publication from the public portal for the purpose of private study or research.

- You may not further distribute the material or use it for any profit-making activity or commercial gain

- You may freely distribute the URL identifying the publication in the public portal 


\title{
Nonlinearity Compensation for Dual-Polarization Signals using Optical Phase Conjugation in a Silicon Waveguide
}

\author{
F. Da Ros ${ }^{1}$, E.P. da Silva ${ }^{1}$, A. Gajda ${ }^{2}$, P.M. Kaminski ${ }^{1}$, V. Cristofori ${ }^{1}$, A. Pęczek ${ }^{3}$, \\ A. Mai ${ }^{2}$, K. Petermann ${ }^{4}$ L. Zimmermann ${ }^{2}$, L.K. Oxenløwe ${ }^{1}$ and M. Galili ${ }^{1}$ \\ 1 DTU Fotonik, Technical University of Denmark, DK-2800 Kgs. Lyngby, Denmark, fdro@fotonik.dtu.dk \\ 2 IHP, Im Technologiepark 25, 15236 Frankfurt(Oder), Germany, gajda@ihp-microelectronics.com \\ 3 IHP Solutions GmbH, Im Technologiepark 25, 15236 Frankfurt (Oder), Germany \\ 4 Institut für Hochfrequenz- und Halbleiter-Systemtechnologien, TU Berlin, Einsteinufer 25, 10587 Berlin, Germany,
}

\begin{abstract}
Improvements in signal-to-noise ratio $(1.2 \mathrm{~dB})$ and transmission reach $(16 \%)$ are demonstrated for dual-polarization WDM 16-QAM signals through nonlinearity compensation by optical phase conjugation in a silicon waveguide with a lateral $\mathrm{p}$-i-n diode.

OCIS codes: (190.4380) Nonlinear optics, four-wave mixing, (060.0060) Fiber optics and optical communications,
\end{abstract}

\section{Introduction}

The continuous increase of throughput in optical communication systems driven is currently facing the strong challenge of Kerr nonlinearity distorting optical signals during fiber transmission. There is today a lack of effective methods to deal with nonlinear distortion, and hence, nonlinearity mitigation and compensation techniques for optical communication systems have been receiving a significant research attention over the past years with a dual focus on digital and all-optical techniques. Digital techniques can provide effective compensation within the analog bandwidth of high-speed electronics, i.e. limiting their effectiveness to intra-channel effects. However, all-optical approaches provide the tools to tackle Kerr effects over broader bandwidths, naturally extending the nonlinear compensation to include inter-channel interaction. Among the all-optical approaches, optical phase conjugation (OPC) has a strong potential, as it can be easily implemented through four-wave mixing (FWM) in nonlinear media. Impressive demonstrations have already been reported using highly nonlinear fibers [1,2], periodically poled lithium niobate [3] and some preliminary results have been shown in a silicon waveguide [4,5]. Nonlinear devices based on silicon are particularly beneficial for future integration. However, in $[4,5]$ the polarization sensitivity of the device limited the demonstrations to single-polarization operation.

In this work, we overcome this limitation with a polarization-diversity scheme using a single silicon waveguide to perform dual-polarization OPC. The silicon waveguide has a lateral p-i-n diode for mitigating free-carrier effects, thus increasing the FWM conversion efficiency [6]. Using such an OPC scheme, improvements in signal-to-noise ratio (SNR) and transmission reach are demonstrated for dispersion-managed transmission of five wavelength division multiplexed (WDM) dual-polarization (DP) 16-quadrature amplitude modulation (QAM) channels.

\section{Experimental setup}

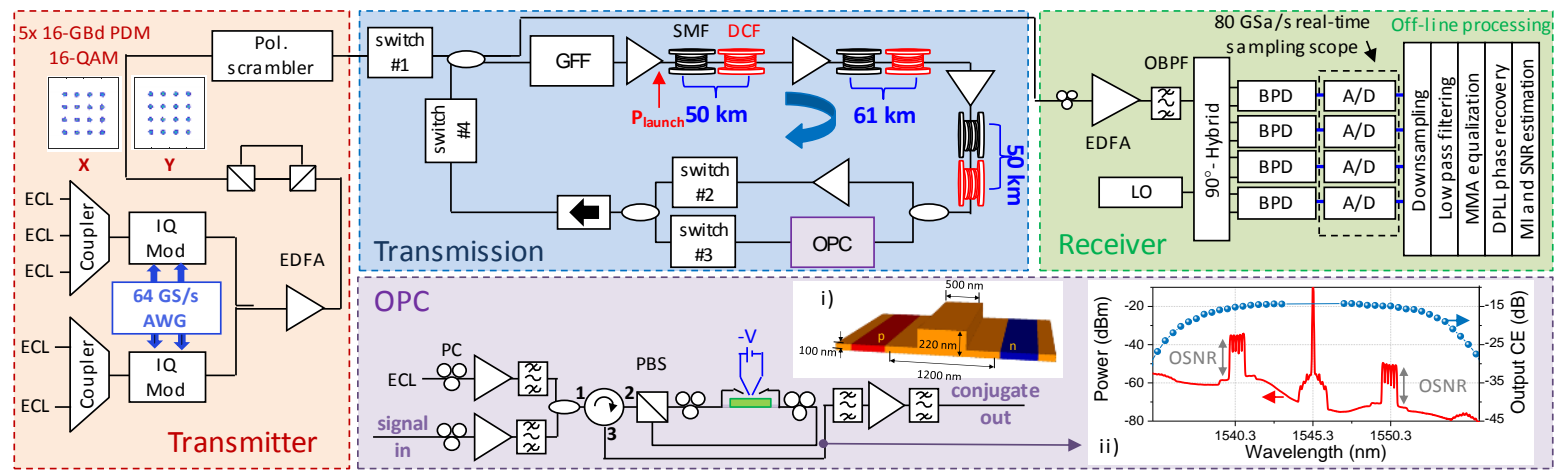

Fig. 1. Experimental setup for the transmission measurements comparing straight transmission to OPC-based transmission. Insets: i) schematic structure of the waveguide with lateral p-i-n diode and ii) optical spectra (red) and CW CE (blue) at port 3 of the circulator in the OPC.

The experimental setup is shown in Fig. 1. Five external cavity lasers (ECLs) on a $25-\mathrm{GHz}$ grid are modulated in two IQ modulators (one for even and one for odd channels) with 16-QAM data at $16 \mathrm{GBd}$. Polarization multiplexing is emulated and the polarization is scrambled. The channels are launched into a recirculating transmission loop (total loop length of $161 \mathrm{~km}$ ) consisting of three dispersion-managed spans of standard single mode fiber (SMF) and dispersion compensating fiber (DCF) with lumped erbium-doped fiber amplifiers (EDFAs). Acousto-optical switches enable selecting either the OPC path (switch \#3) or simple EDFA-based amplification (switch \#2). 
The OPC is based on a single-pump (1545.3 nm, $22 \mathrm{dBm}$ pump power) FWM stage in a 3-cm silicon waveguide with a lateral p-i-n diode as in Fig. 1(i). The waveguide, fabricated in the BiCMOS pilot line of IHP [5,6], is characterized by an insertion loss of $11.5 \mathrm{~dB}$ at $-30 \mathrm{~V}$ of reverse bias applied to the diode. The low propagation loss $(<1 \mathrm{~dB} / \mathrm{cm})$ and lateral diode enable an output conversion efficiency (CE) of $-15 \mathrm{~dB}$. The conversion bandwidth is approx. $13 \mathrm{~nm}$ (Fig. 1(ii)) and no optical signal to noise ratio (OSNR) degradation is observed after conversion. The grating couplers are strongly polarization sensitive, requiring the use of a polarization-diversity scheme to enable processing of DP signals. The two signal polarizations are split and counter propagated in the same waveguide resulting in two counter-propagating co-polarized FWM processes taking place. At the output of the polarizationdiversity loop, the two signal polarizations are recombined with stable relative phase. The DP conjugate idlers are selected by optical bandpass filters (OBPFs) and further transmitted in the recirculating loop before being received in a pre-amplified coherent receiver based on 80-GSa/s analog-to-digital (A/D) converters followed by offline digital signal processing (as listed in Fig. 1).

\section{Transmission results}

The signal performance after transmission has been evaluated in terms of mutual information (MI) and received SNR estimated from the received waveforms as in [7]. MI and SNR are measured as functions of the launched power into each transmission span and comparison between straight (no OPC) and OPC (OPC after three loop turns) transmission is shown in Fig. 2. OPC shifts the optimum launched power by approx. $3 \mathrm{~dB}$ and enables an increase of $0.4 \mathrm{bit} / 4 \mathrm{D}$ symbol in MI and of $1.2 \mathrm{~dB}$ in SNR for 966-km transmission (OPC after $483 \mathrm{~km}$ ). Additionally, after 1127-km of OPC transmission (7 loop turns, OPC still after $483 \mathrm{~km}$ ), the signal quality is still higher than for straight transmission after $966 \mathrm{~km}$, resulting in a transmission reach extension of $16 \%$. Finally, the constellation diagrams of Fig. 2(c) further highlight the signal quality improvement by the nonlinearity compensation achieved by OPC in the silicon waveguide.
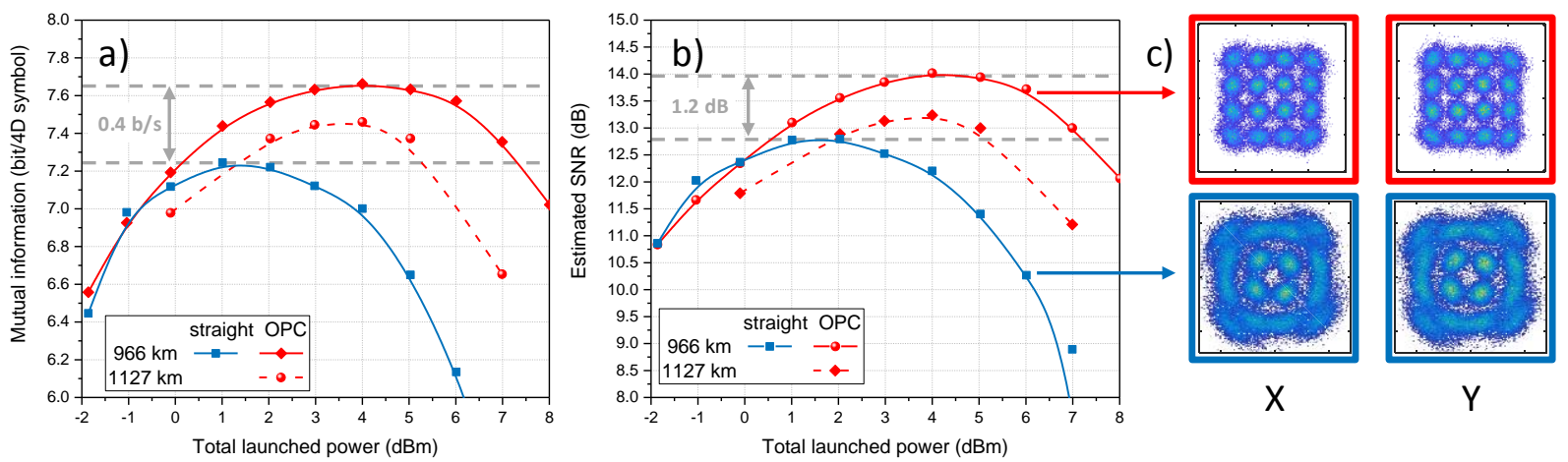

Fig. 2. Estimated receiver MI (a) and SNR (b) of the central WDM channel for straight and OPC-based transmission. c) Constellation diagrams for 966-km straight (blue, bottom) and 966-km OPC-based (red, top) transmission at a launched power of $+6 \mathrm{dBm}$.

\section{Conclusions}

A dual-polarization OPC scheme using a silicon waveguide with a lateral $\mathrm{p}-\mathrm{i}-\mathrm{n}$ diode enables nonlinearity compensation of PDM data signals in a dispersion-managed transmission link. Signal-to-noise ratio and transmission reach improvements of $1.2 \mathrm{~dB}$ (SNR) and $16 \%$ are reported, respectively, by using the OPC scheme.

\section{Acknowledgements}

This work was supported by the DFF project NANO-SPECs (DFF-4005-00558B), the DNRF Research Centre of Excellence, SPOC (ref. DNRF123), and DFG projects SFB 787, ZI 1283/3-1 and PE319/36.1.

\section{References}

[1] A.D. Ellis, et al., " $4 \mathrm{~Tb} / \mathrm{s}$ transmission reach enhancement using $10 \times 400 \mathrm{~Gb} / \mathrm{s}$ super-channels and polarization insensitive dual band optical phase conjugation," J. of Lightw. Technol. 34(8), 1717-1723 (2016).

[2] I. Sackey, et al., "Kerr nonlinearity mitigation in 5×28-GBd PDM 16-QAM signal transmission over a dispersion-uncompensated link with backward-pumped distributed Raman amplification," Opt. Expr. 22(22), 27381-27391 (2014).

[3] T. Umeki, et al., "Simultaneous nonlinearity mitigation in $92 \times 180$-Gbit/s PDM-16QAM transmission over $3840 \mathrm{~km}$ using PPLN-based guard-band-less optical phase conjugation,” Opt. Expr. 24(15), 16945-16951 (2016).

[4] D. Vukovic, et al., "Multichannel nonlinear distortion compensation using optical phase conjugation in a silicon nanowire," Opt. Expr. 23(3), 3640-3646 (2015).

[5] A. Gajda, et al., "Silicon waveguide with lateral p-i-n diode for nonlinearity compensation by on-chip optical phase conjugation," in Proc. OFC 2018, paper W3E.4.

[6] A. Gajda, et al., "Highly efficient CW parametric conversion at $1550 \mathrm{~nm}$ in SOI waveguides by reverse biased p-i-n junction," Opt. Expr. 20(12), 13100-13107 (2012).

[7] M.P. Yankov et al., "Constellation Shaping for WDM Systems Using 256QAM/1024QAM With Probabilistic Optimization,” J. of Lightw. Technol. 34(22), 5146-5156 (2016). 